\title{
Exploring the Meanings of Usage about Onomatopoeia and Mimetic Words in a Child Play Situation
}

\author{
Yoon Mi Kim, Eunju Yun \\ 유아 놀이에서 의성어·의태어 사용 의미 탐구 \\ 김윤미, 윤은주 \\ 숙명여자대학교 아동복지학과
}

Department of Child Welfare and Studies, Sookmyung Women's University, Seoul, Korea

Objective: The aim of this study was to examine the meanings of onomatopoeia and mimetic words contextually used contextually when children play together.

Methods: The participants included 40 children (ages 3-5 years) attending "M Daycare Center" in Seoul and "S Daycare Center" in Seongnam (a city in Gyeonggi-do). Twenty rounds of play observations were conducted at the centers. Once per week from May to October 2015.

Results: The onomatopoeia and mimetic words observed were primarily relate to physical movements, sounds, and shapes. These types relate to Max van Manen's life-world existentials, correlating with spatiality, corporeality, and relationality. The characteristics of onomatopoeic and mimetic words used were additive and were used by the children to refine and diversify their language skills and enrich their linguistic imaginations.

Conclusion: Onomatopoeic and mimetic words help children design their own play situations based on their creativity and help them share the play with their peers.

Keywords: onomatopoeia, mimetic, play, qualitative research

\section{서론}

유아들의 놀이 순간을 주의 깊게 살펴본 경험이 있는 성인이 라면 유아들이 이해하기 힘든 단어와 문장을 쉴 새 없이 쏟아 내는 장면을 어렵지 않게 목격할 수 있다. 문법체계의 법칙이 무시된 의미 없는 음성처럼 들릴 수도 있지만, 놀이 속 유아들 의 말 주고받음에 주의를 기울이면 곧 유아들이 놀이 속에서 자신들만의 새로운 언어를 만들고 규칙을 형성하면서 능숙하 게 의사소통하고 있다는 점을 알게 된다. 본 연구자들은 이런

Corresponding Author: Eunju Yun, Division of Child Welfare and Studies, Sookmyung Women's University, 100, Cheongpa-ro 47-gil, Yongsan-gu, Seoul, Korea

E-mail: eunjuyun@sookmyung.ac.kr
현상을 유아들의 놀이 속에서 관찰하였고 그들이 사용하는 독 특한 형태의 언어가 바로 의성어·의태어의 범주에 속한다는 것을 알게 되면서 그 특성과 의미에 주목하기 시작하였다. 이 것이 본 연구의 출발점이다.

일반적으로 의성어·의태어는 청각, 시각, 촉각, 미각, 통각 등 인간의 감각적 인식의 근거가 되는 오감에서 출발하는 언 어 형태로, 의성어는 사람이나 사물의 소리를 흥내 낸 말, 의태 어는 모양, 태도, 행동 등의 양태를 묘사한 말로 지칭하고 있 다(The National Institute of the Korean Language [NIKL], 1999).

(c)The Korean Association of Child Studies

This is an Open Access article distributed under the terms of the Creative Commons Attribution Non-Commercial License (http:// creativecommons.org/licenses/by-nc/4.0) which permits unrestricted noncommercial use, distribution, and reproduction in any medium, provided the original work is properly cited. 
이 같이 정의되지만 실제로 의성어와 의태어를 따로 분류하기 란 사용한 사람의 사용 의도와 실질적 의미를 정확하게 파악 해야하는 매우 어려운 과정이며 국어학자들에게 조차도 조심 스러운 일에 속한다(Chae, 2003). 따라서 본 연구에서는 의성 어와 의태어가 의성의태어의 하위 개념어 범주 안에 속하므로 (Nam, 1993) 의성어 - 의태어로 통용하여 사용하고자 한다.

의성어 - 의태어는 그 근원이 감성언어로 남녀구분 할 것 없 이 누구나 직감적이고 감각적인 이해가 가능하며 어린 아동 부터 어른에 이르기까지 연령 구분 없이 통용되는 유일무이 한 언어 형태다(S. B. Bae \& Park, 2012; Chae, 2003; K.-O. Sung, 1993). 성인과 아동 모두 이해 가능한 공통 언어라는 의미에 서 의성어·의태어는 아동의 언어 획득의 기반이 되고(S. B. $\mathrm{Bae} \&$ Park, 2012) 언어 발달 측면에서 언어 표현의 지표가 된 다(Y.-T. Kim, Yang, \& Lim, 2014). 또한 의성어 - 의태어는 다른 언어 형태와는 차별화된 독특한 특성을 지니고 있는데 구체적 특성은 다음과 같다.

첫째, 의성어 - 의태어는 리듬감이 강한 감각적인 어휘이자 음운적 특성을 가지며, 이러한 특성은 직접인용과 반복 형태 로 쓰이면서 표현을 극대화시킨다(S. B. Bae \& Park, 2012). 둘 째, 의성어 - 의태어는 표현의 폭이 넓게 허용되기에 개인이 새 롭게 만든 말이어도 쉽게 사회성을 획득하며 그에 따라 개개 인만의 독특한 사고와 감각 표현이 가능하도록 만든다(Chae, 2003). 셋째, 의성어 - 의태어는 필연적 연합에 의해 만들어진 어휘가 아니기 때문에 유연성을 획득한다. 이런 이유로 인해 기존의 단어를 복합시키거나 접사를 붙여 파생시키는 것이 가 능하다(You, 2003). 넷째, 의성어 - 의태어는 의미가 응축되어 있기에 주어나 서술어를 생략해도 즉각적인 의미 전달이 가능 하다(Bai, 2013). 다섯째, 의성어 - 의태어는 순수한 우리말로 써 한국어의 $70 \%$ 가 외래어로 구성되어 있다는 점(Chae, 2003) 에서 의성어 - 의태어 사용 독려는 우리말을 잘 보존하는 길이 기도 하다.

위와 같은 의성어 - 의태어의 독특한 특성들은 그 용도와 역 할의 다양성으로 인해 여러 분야에서 다방면으로 연구되어 왔다(H. S. Bae, 2006; Chae, 2002; H. J. Choi \& Lee, 2009; K.O. Sung, 1993). 최근 관련 연구들을 살펴보면 결혼이주여성과 외국인 학습자를 위한 한국어 교육 방안, 한국어 교육의 필요 성, 발달지체 유아의 언어 표현 지도 등 언어학, 심리학, 교육 학 등과 같이 실증주의 연구 분야에서 두각이 드러난다(S. B. Bae \& Park, 2012; Bai, 2013; Y.-B. Choi, 2013; H. J. Choi \& Lee, 2009; Jo, 2005; S. J. Kim, 2014). 그러나 위의 다문화에 치중 된 의성어-의태어 연구경향은 의성어-의태어가 아동의 언
어 표현에 핵심적 역할을 수행한다는 선행연구결과(S. B. Bae \& Park, 2012; Y.-T. Kim et al., 2014)와 배치된, 즉 실제 아동이 의성어-의태어를 어떻게 사용하는지 이해할 수 있는 구체적 인 배경이 되어주는 연구가 부족한 실태 또한 보여주고 있다. 유아의 언어 사용 중 $50 \%$ 가 의성어 - 의태어가 차지하고 있다 는 선행연구를 고려한다면(Y.-T. Kim et al., 2014) 유아 언어의 절반을 이해하기 위해서는 기본적으로 유아의 의성어-의태 어 사용에 대한 관찰과 분석이 선행되어야 할 것이다. 이와 함 께 유아의 풍부한 의성어·의태어 사용이 상상력과 표현력을 높여주며 안정적인 언어발달을 지원해준다는 연구결과(Y.-B. Choi, 2013)는 유아들의 의성어 · 의태어 사용에 대한 탐색의 필요성을 더욱 증가시킨다. 이처럼 유아의 의성어 - 의태어 사 용에 대한 탐구는 매우 기본적이면서 유아 언어를 이해하는데 매우 유용한 방법이다. 유아가 어떤 맥락에서 어떤 방법으로 의성어 - 의태어를 사용하는지와 함께 의성어 - 의태어의 사용 이 언어 발달 측면에서 어떤 의미가 있는지에 대한 연구결과 는 아동의 언어뿐만 아니라 아동의 발달 전반을 이해할 수 있 는 단서를 제공한다는 점에서 의미하는 바가 크다.

최근 유아 언어사용에 대한 연구들이(Ahn, 2014; Im, 2015; Jang, 2015; Jeon, 2013; Kang, 2014; Lee, 2013; M. Y. Sung, 2014) 놀이라는 자연스러운 상황을 지향한다는 점에 착안하여 본 연 구자들은 연구맥락을 이런 경향에 맞추어 놀이상황으로 정하 고 그 가운데 나타나는 의성어 - 의태어를 탐구하고자 하였다. 놀이가 주는 자유로움이 풍부한 언어를 사용하게 만드는 원동 력이 되므로(Vygotsky, 1930/2014) 유아의 의성어·의태어 사 용 또한 다채롭고 다양한 모습으로 발견될 수 있을 것으로 예 상하였다. 놀이라는 자유로운 맥락에서 유아들이 사용하는 의 성어 - 의태어의 유형은 어떠한지, 그리고 나타난 유형을 이해 하기 위하여 van Manen (1990)의 질적 연구 방법의 실존체(공 간성, 신체성, 관계성)를 분석 틀로써 정하였다.

질적 연구의 목표는 경험 내용을 기술하고 나열하여 정리 하는데 있는 것이 아니라, 의미를 파악하는 것이다. 의미 파악 은 단면적인 면으로 밝힐 수 있는 것이 아니기 때문에, 관계, 공간, 체험 및 신체가 서로 어떻게 연관되어 있는지 다양한 각 도로 살펴봄으로써 의식 자체의 모습을 볼 수 있다(Yeu, 2015). Max van Manen은 질적 연구의 주제는 일상생활에서 출발해야 하고 생활세계의 연속적인 연관성을 통해 진정으로 알고자 하 는 의미를 구체화시켜 나아갈 수 있다고 하였다. 생활세계 실 존체(existentials)는 공간성, 신체성, 관계성, 신체성이며 의미 를 살필 수 있는 틀이 되므로 질적 연구의 의미를 찾아가는 과 정이 되어준다(van Manen, 1990). 따라서 본 연구의 주제가 유 
아들의 놀이라는 일상생활 안에서 사용하는 언어에 대한 탐구 라는 점에서 놀이 공간, 유아들의 움직임(신체), 관계들 안에 서 이루어지는 놀이 속 언어의 의미를 살피기 위해 van Manen (1990)의 생활세계 실존체(existentials)를 분석틀로 정하여 의 미를 탐구하고자 하였다.

요약하자면, 본 연구자들은 일상 경험의 본성이나 의미 를 보다 깊이 있게 이해하는 질적 연구 방법을 사용하여(van Manen, 1990), 기존 의성어 - 의태어 연구의 주류를 이루었던 실증주의 연구와는 다른 이론적 배경을 바탕으로 유아 놀이 상황 속 의성어 - 의태어 사용에 대한 의미를 탐색하고자 하였 다. 이러한 연구결과는 유아의 언어 사용에 대한 이해뿐 아니 라 아직 활발히 연구되지 않은 유아의 의성어 - 의태어 사용에 대한 기초 자료가 되어줄 것으로 기대한다.

\section{연구문제 1}

유아 놀이에서 의성어·의태어의 유형은 무엇인가?

\section{연구문제 2}

유아 놀이에서 나타난 의성어-의태어의 유형은 Max van Manen의 실존체(공간성, 신체성, 관계성) 안에서 어떤 영향 을 받는가?

\section{연구문제 3}

유아 놀이에서 의성어-의태어 사용은 유아들에게 어떤 의미 를 가지는가?

\section{연구방법}

\section{사전 관찰}

본 연구의 실제 관찰에 앞서 연구의 적절성 관점을 구성하기 위해 서울시에 위치한 $S$ 어린이집에서 사전관찰을 실시하였 다. 2014년 9월부터 12월까지 주 1회 총 12회 오전 10시부터 11 시 30 분까지 유아들의 오전 일과를 기록하였다. 10 시부터 11 시까지는 이야기 나누기를 시작으로 교사 주도 아래 수업 이 진행되었고 11 시부터 11 시 30 분까지는 자유 선택 활동 시 간이었다. 교사 주도 아래 진행 된 전사 자료와 자유 선택 활동 시간에 기록된 전사 자료는 동영상, 촬영, 현장 노트 등을 활용 하여 기록하였고, 18 시간 관찰 기록의 총 전사 자료의 분량은 $\mathrm{A} 4$ 용지 193장 이었다. 사전관찰을 통해서 교사의 주도 아래
이루어진 수업시간에서는 나타나지 않았지만 유아가 자유로 운 놀이 상황에서 또래들과 의성어-의태어를 빈번하게 사용 하는 언어적 현상을 발견할 수 있었고, 발견한 현상을 토대로 본 연구의 방향성을 정립할 수 있었다.

\section{연구 참여자}

본 연구는 서울특별시에 위치한 $\mathrm{M}$ 어린이집과 성남시에 위 치한 $S$ 어린이집 두 곳을 연구 참여 기관으로 선정하였다. 만 3-5세 유아들을 대상으로 M 어린이집 21명, S 어린이집 19명 으로 총 40명의 유아들을 관찰하였다. $\mathrm{M}$ 어린이집은 만 3-4 세반 10명, 만 4-5세반 11명으로 혼합연령 두 반이었고, S 어 린이집은 만 3 세반 9명, 만 4세반 10명 두 반이었다. 본 연구가 40 명의 유아를 대상으로 관찰하는 까닭에 질적 연구 유형에 어긋난 것으로 잘못 비춰질 수 있다. 질적 연구가 부딪히는 문 제가 바로 정해진 틀이다. 정해진 틀은 없다. 연구 성격과 연구 자가 정한 계획에 따라 한두 명의 개인의 삶을 심층적으로 바 라볼 수 있고, 살피고자 하는 개념에 대해 의미를 찾기 위해 한 집단이나 여러 무리를 연구하기도 한다(van Manen \& Michael, 2012).

만 3-5세 사이의 유아들은 과거 보았던 것과 자신의 생 각을 표현하기 위해 언어를 정교하게 사용하는 시기이므로 (Pence \& Justice, 2008/2010) 유아의 의성어 · 의태어 사용을 구 체적으로 살필 수 있다고 판단하여 연구 참여자의 연령을 만 3-5세 유아로 선택하였다. 연구 참여 기관 선정 기준은 두 곳 모두 자율적 놀이와 개별적 능력을 강조하는 교육관을 추구하 는 곳이었으며, 이러한 교육관은 자유로운 놀이 상황 속 유아 의 의성어 - 의태어 사용을 보고자 하는 본 연구 목적에 적합하 였다.

\section{연구절차 및 자료수집}

실제 연구를 위한 연구 현장 관찰은 2015년 5월 8일부터 10월 26 일까지 대략 6 개월간 주 1 회 관찰 기록이 진행되었다. 5월 말부터 6월 초까지 전염병이 발생하여 관찰이 이루어지지 못 했던 대략 2 주간의 기간을 제외하고 $\mathrm{M}$ 어린이집 10 회, $S$ 어린 이집 10 회로 총 20 회의 관찰이 매주 1 회씩 이루어졌다. 1 시간 혹은 1 시간 30 분 정도의 놀이 관찰은 교사의 수업 계획안을 바탕으로 관찰 일정을 정했다. 관찰 횟수와 시간은 교사의 편 의를 고려하여 교사가 미리 계획하여 준비한 시간과 기간 안 에서만 관찰을 할 수 있었다. 각 어린이집의 일정을 고려하여 
$\mathrm{M}$ 어린이집은 실내 1 시간씩 3 회와 실외 1 시간 30 분씩 7회로 총 13 시간 30 분 정도의 놀이 관찰을 기록하였고, $S$ 어린이집 은 실내 1 시간씩 6 회와 실외 1 시간씩 4 회로 총 10 시간의 놀이 관찰이 이루어졌다. 관찰 시간의 분배와 일정, 장소는 앞서 설 명한대로 교사가 미리 구성한 수업계획안을 토대로 이루어졌 으며 연구 관찰 일정은 Table 1과 같다.

유아들의 놀이 관찰은 놀이가 시작되면 한 무리의 유아들을 대상으로 놀이의 시작부터 끝까지 관찰이 이루어졌다. 바깥 놀 이 활동에서의 놀이 관찰은 이미 사전 관찰에서의 충분한 전사 기록 경험으로 여러 무리의 유아들을 전체적으로 관찰하는 것 이 아니라 한 무리 혹은 두 무리의 유아들을 따라다니며 노트, 녹음, 촬영을 동반하여 기록하였기 때문에 관찰기록에 큰 어 려움이 없었다. 본 연구가 질적 연구라는 점에서 자료 수집이 한 방향으로만 치우쳐 현상이 편향될 수 있다는 점을(Wolcott, 1990) 고려하여 현장에서 틈틈이 작성한 연구자의 현장노트, 놀이 속 언어를 생생하게 기록하기 위한 촬영 및 녹음, 유아들 의 놀이 사진 등의 다양한 자료를 수집하였다. 수집한 자료들 은 기록하는 과정에서 관찰 당시의 기억을 되살려주는 역할을 하였다. 또한 교사들과의 공식적 면담과 비공식적 면담을 통해 유아들의 성향을 파악하려고 노력하였으며 수집된 자료는 교 사와 함께 공유하여 기록의 오류를 최소화하고자 하였다. 가령 연구 참가자의 정서를 이해하는 비언어적인 표현들은 교사와 의 전사자료 공유와 면담들이 분석과정에서 유아의 놀이 속 언 어 사용에 대한 표현을 이해하는 데 도움 되었다.

\section{자료분석}

자료 분석은 현장노트와 녹음 및 동영상 녹화를 전사한 후 의 성어 - 의태어를 사용하여 놀이가 진행된 장면을 분류하였다. 분류한 전사 자료의 양은 총 $\mathrm{A} 4$ 용지 98 매 분량으로 $\mathrm{M}$ 어린이 집은 A4 용지 61매 분량, S 어린이집은 A4 용지 37매 분량이었 다. 이를 토대로 Saldana의 에믹 코딩 (emic coding)과 구조 코딩 (structural coding)을 실시하였다. 에믹 코딩은 참여자의 관점 에 따라서 자료를 분석하여 있는 그대로의 언어로 표현하는
것이고, 구조 코딩은 연구문제를 설정하여 답을 찾아가는 과 정이다(Jeon, 2015). 따라서 의성어 - 의태어를 사용했던 대화 자료를 중심으로 정렬시킨 후 사용된 의성어·의태어만을 추 출하여 표로 만들었다. 관찰에서 총 67 개의 의성어 - 의태어가 사용되었고, 코딩 자료들을 토대로 분석이 이루어졌다. 분석 은 코딩 자료들을 토대로 1 차로 분류된 의성어-의태어를 유 형별로 묶어 분석을 진행하면서, Max van Manen의 생활세계 에 해당하는 공간, 신체, 관계 속에서 의성어 - 의태어 사용이 어떻게 변화되며 나타나는지를 살펴보았다(van Manen, 1990). 마지막 3 차 분류 작업은 1차 2 차 코딩 내용을 구조 코딩으로 의성어 - 의태어 사용의 개념과 의미를 찾아 분석하였다.

\section{연구의 타당도}

질적 연구에서 연구의 타당도란 연구를 진행하고 참고하는 모 든 사람들이 현장에 참여하고, 자료를 기록하고, 자료를 공유 하고, 기록된 자료를 분석하는 일련의 과정들을 함께 검토하 여 이론과 자료의 교차점에서 적절한 균형을 이맀는지를 의 미한다(Graue \& Walsh, 1998/2014). 이를 확보하기 위하여 van Manen (1990)의 제언을 반영하여 조언자, 검토자, 전문가 확 인을 실시하였다. 조언자 및 전문가 확인은 본 연구의 공동 연 구자이자 질적 연구 경험이 풍부한 교수 1 인이 참여하여 논문 에 대한 전반적인 과정을 함께 논의하였고, 검토자는 연구 현 장 관찰에 함께 참여한 교사들로 전사 자료를 공유하여 결과 를 검토하도록 하였다.

\section{연구결과}

\section{유아들이 놀이에서 사용하는 의성어·의태어 유형}

본 연구에서는 놀이에서 나타난 유아의 의성어-의태어를 살 펴봤으며 크게 세 가지 유형으로 나타났다. 첫째, 움직임 및 행

Table 1

Observational Research Procedure

\begin{tabular}{clll}
\hline \multicolumn{1}{c}{ Research schedule } & \multicolumn{1}{c}{ Research participants } & \multicolumn{1}{c}{ Free choice activity } & \multicolumn{1}{c}{ Outdoor playing activity } \\
\hline May 8 to July 18, 2015 & M Daycare Center & High level class, 2 times & High-level class, 7 times \\
& & Low level class, 1 time & Low-level class, 7times \\
August 17 to October 26, 2015 & S Daycare Center & High level class, 3 times & High-level class, 2 times \\
& & Low level class, 3 times & Low-level class, 2 times \\
\hline
\end{tabular}


동을 표현하는 유형, 둘째, 소리를 표현하는 유형, 마지막으로 형태를 표현하는 유형으로 나타났다. 이처럼 유형별로 묶어 분류하여 살펴본 까닭은 새로운 시도에 대한 기여가 아니라 유아가 놀이에서 어떤 형태의 의성어 - 의태어를 사용하는지 파악해보고 이해해보는 과정이었다. 연구를 통해 나타난 의성 어-의태어는 흔히 알 수 있는 의성어 - 의태어의 형태도 보였 고 생소한 형태의 의성어-의태어도 나타났다. 의성어 - 의태
어 유형은 의성어 - 의태어 개념(Chae, 2003)을 바탕으로 분류 하였다. 본 연구 관찰 기간 동안 나타난 의성어 - 의태어는 총 67 개였으며 Table 2와 같다.

$$
\text { 움직임 표현의 의성어·의태어 }
$$

놀이의 가장 큰 특성은 놀이의 자유성이다. 놀이의 자유성

Table 2

Onomatopoeia and Mimetic Words in Play

\begin{tabular}{|c|c|c|c|}
\hline $\begin{array}{c}\text { Type of onomatopoeia and } \\
\text { mimetic words }\end{array}$ & Example & $\begin{array}{r}\text { Type of onomatopoei } \\
\text { mimetic words }\end{array}$ & Example \\
\hline Movement & Du-duk & Sound & $\mathrm{Cu}-\mathrm{u}-\mathrm{u}-\mathrm{u}$ \\
\hline Movement & Bingle-bingle & Sound & Eichwi \\
\hline Movement & Whik & Sound & Tok-tok-tok \\
\hline Movement & Youngcha-Youngcha & Sound & Bee-bee \\
\hline Movement & Yap-yap-yap & Sound & Ttareung \\
\hline Movement & Utha-utha & Sound & Chu-u-u-u \\
\hline Movement & Whi-ing & Sound & Tang-tang-tang \\
\hline Movement & Su-u-u-uk & Sound & Wingwing i \\
\hline Movement & Bing-bing & Shape & Ppyong-ppyong \\
\hline Movement & Syuk & Shape & Yorijoring \\
\hline Movement & Eurachacha & Shape & Ttak-ttak \\
\hline Movement & Pook-pook & Shape & Kkuyeok-kkuyeok \\
\hline Movement & Seukseuk-saksak & Shape & Puuuk \\
\hline Movement & Wheel-wheel & Shape & Yuck \\
\hline Movement & Bang-bang & Shape & Jju-jju \\
\hline Sound & Wiing-wiing & Shape & Toktoki \\
\hline Sound & Duu-duu-duu-duu & Shape & Byungbyung i \\
\hline Sound & Cheol-leung & Shape & Donggeul-donggeul \\
\hline Sound & Thang-thang-thang & Feeling & Piyu-piyu \\
\hline Sound & Ya-ow & Emphasis & Jjan \\
\hline Sound & Jjeop-jjeop & Emphasis & Ppaeng \\
\hline Sound & Vroom-vroom & & \\
\hline
\end{tabular}


은 유아의 신체를 자유롭게 해주고 활동적으로 만들어주며 (Jeon, 2013) 놀이를 통해 상상하는 것들을 움직임으로 형상화 할 수 있게 한다(Oh, Choi, \& Jeon, 2014). 놀이에서 나타난 의 성어-의태어의 유형은 놀이의 가장 큰 특성인 놀이의 자유성 의 영향을 받아 움직임 및 행동을 표현하는 유형이 가장 빈번 하게 사용되었으며, 함축적으로 표현할 수 있는 의성어 - 의태 어의 독특한 특성은 유아의 움직임과 행동을 보다 구체화 시 켜주었다.

다음 관찰 사례를 통해 움직임 및 행동을 나타내는 의성 어·의태어 유형을 살펴볼 수 있다.

\section{관찰 1}

인O(만 4세): (토끼를 보고 뛰어가며) 토끼야! 놀자! 여자유아들: (웃음소리) 하하하하

남자유아들: (합창하듯) 토끼야 놀자!!

남자유아1: 달려! 달려! 두둑두둑! 두둑! 달려!

남자유아들: 두둑! 두둑! 달려라! 달려!

여자유아들: 웃겨 - 달리기래! 두둑두둑!

(M 어린이집, 2015. 05. 08)

\section{관찰 2}

휘○(만 4세): 여기봐바 여기. 여기 나뭇가지로 파 현 $\bigcirc$ (만 4세): 영차. 영차.

휘○(만 4세): 내가 해볼게. 비켜봐. 영차. 영차.

현 $\bigcirc$ (만 4세): 여기 나무. 나무. 영차로 파...

(M 어린이집, 2015. 05. 11)

위의 관찰 1 의 배경은 활동의 제약이 없는 넓은 공터였다. 유아들은 토끼를 발견하고 토끼 뒤를 쫓고 있었다. 하지만 갑 자기 토끼가 사라졌고 유아들은 토끼를 찾기 위해 분주하게 뛰어 다녔다. 갑자기 달리고 있던 유아 한명이 큰 소리로 "달 려! 두둑!”이라고 외쳤고 함께 달리던 유아들도 “두둑두둑”이 라고 외쳤다.

관찰 2의 배경은 어린이집 근처 공원이었고 유아들은 바닥 에 떨어져있는 나뭇가지를 들고 흙을 파고 있었다. 그 중 남자 2 명의 유아가 개미를 발견하고 소리를 지르며 나뭇가지로 흙 을 파기 시작했다. 땅이 단단해서 훍이 잘 파지지 않자 현 $\bigcirc$ 는 조금 과장된 행동을 보이며 “영차영차" 소리를 내며 휽을 팠 다. 옆에서 그 모습을 지켜보던 휘도 “영차영차”라는 표현과 함께 크게 움직이며 훍을 파기 시작했다.

위의 두 관찰 사례를 살펴보면 유아들은 자신들의 움직임
및 행동을 함축적으로 표현하기 위해 의성어·의태어를 사용 했으며 유아들의 행위 및 행동이 구체적으로 표현되었다.

\section{소리 표현의 의성어·의태어}

유아는 자신이 과거 들었던 소리 혹은 현재 듣고 있는 소리 를 인지하여 입으로 내뱉어 표현한다. 모국어를 배우는 과정 은 듣기, 말하기, 쓰기, 읽기로 자연스럽게 확장되는데(Roh, 2005), 이때 유아가 들은 것을 표현하고자 하는 능력이 언어학 습 모델 중 가장 첫 단계가 된다. 때문에 유아가 소리를 표현하 기 위해 의성어- 의태어를 사용하는 현상은 놀이라는 맥락 안 에서 자연스럽게 나타났고, 놀이를 함께 구성하는 또래에게 표현하고 싶은 소리의 형상을 구체화하기 위해서 의성어·의 태어를 사용했다.

다음 관찰 사례들을 통해 소리를 표현하는 의성어 - 의태어 유형을 살펴볼 수 있다.

관찰 3

승 $\mathrm{O}$ (만 5세): 어? 모야? 모가 휙 날라 갔어!

현 $\bigcirc$ (만 4세): 어? 어? 모가?

휘○(만 5세): 방금 위잉위잉 했잖아. 위잉위잉.

현 $\bigcirc($ 만 4세): 진짜? (궁금한 듯이) 어디? 어디? 어디서 윙 윙했어?

(M 어린이집, 2015. 05. 08)

관찰 4

대O, 규○(만 4세): (퍼즐맞추기를 하고 있다.)

우O(만 4세): (퍼즐 시계를 3시에 맞추며) 땡땡땡! 땡땡 땡! 울립니다. 땡땡땡!

대 $\bigcirc$ (만 4세): (주위를 두리번 거리며) 어? 괴물 없는데?

웅(만 4세): 아니 땡땡땡이라고!

대 $\bigcirc$, 규○(만 4세): 아...(퍼즐 시계를 쳐다보며 알겠다는 듯)

(M 어린이집, 2015. 06. 08)

관찰 3의 놀이 상황은 유아들이 바깥 공터에서 돗자리를 깔 아놓고 이야기를 나누고 있었다. 어디선가 파리가 나타났는지 승이이는 벌떡 일어나 주위를 두리번거렸다. 파리가 나타났다 가 갑자기 사라진 것을 의식하고 파리를 표현하기 위해 “위잉 위잉”이라고 또래 유아들에게 표현했다. 함께 놀이를 하던 또 래 유아 역시 “위잉위잉”이라고 파리를 표현한 의성어·의태 
어를 이해하곤 “어디서 윙윙했어?”라고 묻는다.

관찰 4는 자유 선택 활동 시간에 유아들이 테이블에 퍼즐을 맞추고 있었다. 대 $\bigcirc$, 규과 함께 퍼즐 놀이를 하고 싶어 주위 를 맴돌던 우은 퍼즐 시계를 손에 들고 옆에 앉는다. 웅은 혼자 퍼즐 시계의 시계바늘을 돌리더니 시계가 정각에 울리는 소리를 냈다. 우의 “땡땡땡”은 시계를 뜻하고 있었으며 대 $\bigcirc$ 가 상대방의 의도를 파악하지 못했지만 “땡땡땡” 이 시계를 뜻 하고 있음을 알아차렸다.

유아는 과거 자신이 들었던 소리와 소리로 형태를 표현할 수 있는 의성어 - 의태어를 사용하였으며 이러한 유형은 소리 로 형태를 표현할 수 있는 의성어·의태어의 특성 중 하나이 다. 의성어-의태어가 갖고 있는 독특한 특성이 유아의 언어표 현에 영향을 미치며 사용한다는 것을 살펴볼 수 있었다.

\section{형태 표현의 의성어·의태어}

만 3-5세 사이의 유아들은 자신의 생각과 과거 보았던 것을 표현하기 위해 언어를 정교하게 사용하기 시작한다. 이러한 능력은 유아가 이해한 것을 표현하기 위해 단어의 양이 점 점 늘어나게 되는데, 맥락화된 언어가 끊임없는 상호작용을 통해 탈맥락화된 언어로 정교하게 나타난다(Pence \& Justice, 2009/2010). 특히 유아는 추상적인 형태와 과거 경험을 통해 습득했던 것을 표현하기 위해 의성어·의태어를 사용하였고, 이러한 현상은 놀이를 통해 재현되었다.

다음 관찰들을 살펴보면 형태를 표현하기 위해 어떻게 의 성어·의태어를 사용하는지 알 수 있다.

\section{관찰 5}

민 $\bigcirc$ (만 4세): (경에게 그릇을 보이며) 자 라면먹자! 경 $\bigcirc$ (만 4세): (라면 먹는 흥내를 내며) 후루룩 쩝쩝 후루 룩! 후루룩 쩝쩝쩝!

송(만 4세): (그릇을 가리키며) 이거 라면! 민아 라면 은 이게 라면이야 라면!

민 $\bigcirc$ (만 4세): (송ㄱㄱㅏ 가리킨 곳으로 경ㄱㄱㅏ 가려고 하 자) 안돼! 가는거 아니야!

(M 어린이집, 2015. 06. 08)

관찰 6

대 $\bigcirc$ (만 4세): (솔방울을 양발로 밟으며) 너무 딱딱해. 딱 딱하다구!

송 $\bigcirc$ (만 4세): (대 $\bigcirc$ 의 한팔을 잡아준다)
대 $\bigcirc$ (만 4세): (솔방울을 한발씩 밟으며) 에잇!! 송ㅇㅁ만 4세): (한 발을 크게 들더니 솔방울을 내리치며) 요걸 탁! 대O(만 4세): 한번에 탁! 우 $\mathrm{O}$ (만 4세): 한번에 탁! 이렇게 탁!

우으, 송(만 4세): 하하!! 에잇! 딱딱해! 딱딱하다구!

(M 어린이집, 2015. 06. 15)

관찰 5의 “후루룩 쩝쩝”은 라면을 표현하기 위해 사용하였 음을 유추해볼 수 있다. 관찰 도중 소꿉놀이를 하고 있는 유아 들의 놀이에서 의성어-의태어를 사용하는 현상이 자주 목격 되었는데 이는 형태를 표현하기 위한 목적으로 사용하고 있다 는 것을 살필 수 있다. 위의 관찰 5에서 사용된 “후루룩 쩝쩝" 을 따로 살피면 소리를 듣고 파생된 형태로 보이지만, 유아들 이 놀이에서 라면이라는 형태를 표현하기 위해서 "후루룩 쩝 쩝”의 의성어 - 의태어를 사용하였고 함께 놀이를 즐기고 있는 유아 또한 사용된 의성어 - 의태어를 이해하고 있다는 것을 알 수 있다. 이러한 현상은 유아들이 상상 속 형태를 표현하기 위 해 의성어·의태어를 사용했다는 것을 살필 수 있다.

관찰 6 역시 사물의 성질에 대한 형태를 설명하기 위해 “딱 딱" 혹은 “딱딱해.”라는 의성어 - 의태어를 사용하였다. 기본 적으로 의성어가 소리라면 의태어는 소리의 모방과는 관계없 는 양태를 상징적으로 묘사함으로써 성립된 상징어로(NIKL, 1999), 단어를 복합시키거나 접사를 붙여 파생시키는 것을 가 능하게 하는 의성어 · 의태어의 독특한 특성이(Chae, 2003) "딱 딱해."라는 단단한 성질의 양태를 상징적으로 묘사했다. "-하 다, -해, -했다'는 파생접미사로 '딱딱' 뒤에 '-해'의 파생접미사 가 합해져 부사적 기능을 하는 의성어-의태어가 사용되었다 (You, 2003). 의성어 - 의태어는 품사를 넘나들며 우리말에서 유일하게 유형론적으로 독특한 지위를 차지한다. 파생접미사 에 의해 동사, 형용사로 활발하게 파생되기도 하고 문장에서 관형어, 부사어, 서술어로 기능하기도 한다(Chae, 2002). 따라 서 위의 관찰 6 에서 사용된 "딱딱해."는 유아들이 생각했을 때 솔방울이 밟아도 형태가 변하지 않기 때문에 단단하다고 생각 했으며 그 성질의 형태를 표현하기 위해 "딱딱해."라는 부사 적 기능의 의성어 - 의태어를 사용하였다는 것을 볼 수 있다.

이처럼 어떤 사물의 형태 혹은 과거 자신이 보았던 형태를 상대방에게 표현한다는 것은 유아에게 쉬운 표현은 아니지만 의성어-의태어를 사용하여 의도한 바를 전달하는 유아의 놀 라운 의사소통 능력을 함께 엿볼 수 있다. 


\section{공간성, 신체성, 관계성이 공존하는 의성어·의태어}

유아들의 놀이에서 사용된 의성어-의태어 유형은 크게 세 가 지로 움직임을 표현하는 유형, 소리를 표현하는 유형, 형태를 표현하는 유형으로 나타났다. 이러한 유형의 의성어-의태어 는 놀이가 이루어지는 공간 속에서 신체를 움직이며 서로 관 계를 맺는 상호작용 과정 속에서 나타났다. 이러한 연속적인 반응 속 의성어 - 의태어 사용은 Max van Manen의 생활세계 실존체인 공간성, 신체성, 관계성과 밀접한 관련이 있었으며 의성어-의태어의 유형은 실존적 근거에 영향을 받고 있었다 (van Manen, 1990). 자료 분석 작업을 통해 드러난 참여자들의 놀이 속에서 실존적 근거인 공간성, 신체성, 관계성을 통해 의 성어·의태어가 나타나는 현상을 이해해보고자 한다.

\section{공간성과 신체성의 공존}

공간은 놀이가 이루어지는 주 무대로서 공간의 크기는 놀이를 동적으로 만들기도 하고, 정적으로 만들어주기도 한다. 공간 의 크기만으로 동적인 놀이와 정적인 놀이가 구분되어 나타나 지는 않았지만 공간의 제약이 없다는 것은 유아들의 움직임을 좀 더 활발하게 해주는 요소임에는 분명했다. 놀이에서 공간 과 신체는 함께 공존하며 서로 영향을 주고받는 존재였고, 의 성어 - 의태어 유형 또한 이 둘의 영향을 받으며 다양한 모습으 로 나타났다. 이러한 현상들은 다음 관찰들을 통해 살펴볼 수 있다.

\section{관찰 7}

예ᄋ(만 5세): (꽃밭 주위를 돌며) 빙글빙글!(점점 소리가 커진다.) 돈다구 -!

시 $\bigcirc$ (만 4세): (예○이를 따라 돌며)돈다.. 돈다... 빙글빙 글 빙글빙글

현 $\bigcirc$ (만 5세): (한 바퀴 돌고 멈추며) 어...아니야. 토끼가 아니잖아.

예 $\bigcirc$ (만 5세): (천천히 꽃밭 주위를 돌면서) 우리는 빙글 빙글 돌고 있어. 토끼를 찾아서.

현O(만 5세): 아니! 토끼 여기 없잖아! (짜증 섞인 목소리)

(M 어린이집, 2015. 05. 08)

유아들은 어린이집 근처에 있는 공원에서 바깥 놀이 활동 중이었다. 큰 공터가 있었고 그곳을 자유롭게 뛰어다니고 있 었다. 큰 공간 속에서 유아들의 신체는 자유로움을 만끽하고
있었고 움직임 또한 자유로웠다. 큰 공간 속 놀이 상황은 유아 들의 신체를 마음껏 움직일 수 있게 해주었고 움직임 또한 컸 다. 의성어 - 의태어 사용 역시 큰 공간에서의 신체의 움직임으 로 인하여 움직임을 표현하는 유형의 의성어 - 의태어 사용이 빈번하게 나타났으며 공간성과 신체성이 함께 공존하여 영향 을 받아 의성어-의태어 사용에 영향을 미치고 있음을 살펴볼 수 있었다.

\section{공간성과 관계성의 공존}

놀이가 이루어지는 공간은 유아들이 의미를 부여하고 관계가 발생되는 중요한 요인 중 하나이다. 놀이 속에서 특정 공간에 의미를 부여하면서 놀이 관계를 맺는 유아들과 함께 공간을 공유하고 관계를 맺게 된다(Jeon, 2013). 공간의 의미가 함께 공유되지 않으면 관계를 맺으며 놀이를 진행할 수 없는데, 공 간과 관계는 함께 의미를 공유하고 공유 받으면 공존하게 된 다. 이때 의성어 - 의태어는 놀이 과정을 더욱 탄탄하게 만들어 주는 존재로 공유된다.

다음 관찰을 통해 공간에 의미가 부여되고 관계가 맺어지 는 과정 속에서 의성어·의태어가 소통하는 매개체로 작용되 고 있음을 살펴볼 수 있다.

관찰 8

경 $\bigcirc$ (만 3세): (자리에 앉아 아기 인형을 앞뒤로 흔들면 서) 우리 애기! 쭈쭈먹는 애기야. 쭈쭈 먹을까? 아니아니 지이보다 작은 애기!

지 $\bigcirc$ (만 3세): (갑자기 경에게게 관심을 보이며) 오... 애기 얌얌하지마! 얌얌하지마! (경이가 안고 있는 아기 인형에 게 그릇을 주면서)

경 $\bigcirc$ (만 3세): 이거 애기 그릇이야?

지O(만 3세): (호들갑스런 말투로) 오!! 뜨거! 뜨거! 뜨거 워요! 뜨겁다구요.

경(만 3세): (고개를 끄덕이며) 맞아. 진짜 아기니깐.

(S 어린이집, 2015. 08. 17)

관찰 8 에서의 공간은 역할놀이영역으로 유아들에게 이 공 간은 집이 되었다. 공간에 의미를 부여하며 관계를 맺는 과정 에서 집이라는 공간을 표현하기 위해 “쭈쭈”라는 의성어·의 태어를 사용하고 있음을 살펴볼 수 있다. 누군가와 관계를 맺 으며 놀이가 이루어진다는 것은 함께 놀이가 공유된다는 뜻 이기도 하다. 함께 공유된 공간 속에서 관계를 맺으며 의성 
어 - 의태어는 놀이를 공유하기 위한 수단이 되어주기도 한다.

\section{신체성과 관계성의 공존}

신체는 일차적으로 촉각이며 촉각은 운동감각이다. 모든 감각 은 동시에 촉각이라 지칭할 수 있는 운동감각이다. 촉각은 가 장 처음 이루어지는 운동감각이다(Z. Choi, 2009). 이처럼 촉각 을 시작으로 움직임이 시작되고 신체 움직임의 수반은 당연하 다. 그리고 놀이 관계는 이러한 움직임의 반응에 따라 맺어진 다. 움직임의 활동량과 놀이 관계는 어떤 모습으로 공존되느냐 에 따라 의성어 - 의태어 또한 영향을 받으며 나타났다. 큰 움직 임을 요구하는 놀이에서는 대부분 남자 유아들이 놀이를 공유 하며 관계를 맺었고, 반대로 작은 움직임을 요구하는 놀이에서 는 여자 유아들이 놀이를 공유하며 관계를 맺었다. 그리고 그 속에서 의성어·의태어 또한 다양한 모습으로 나타났다.

\section{관찰 9}

성 $\mathrm{O}$ (만 4세): 못간다! $\mathrm{OOOOO}$ (애니메이션 캐릭터 이름)! 피유우웅!

민(만 5세): 나 갈거야!

성○(만 4세): 못간다!! $\mathrm{OOOOO}$ (애니메이션 캐릭터 이름)! $\bigcirc$ (애니메이션 캐릭터 이름)! 피유우우우웅! (포즈를 취 하며 애니메이션 속 캐릭터가 하는 행동을 따라한다.)

민 $\bigcirc$ (만 5세): 나 갈거라구!(성를 뿌리친다.)

성○(만 4세): 물리치자! 포스 얍! 얍! 얍! (민 $\bigcirc$ 앞을 가 로막으며)

민(만 5세): (갑자기 울음을 터트린다.) 으....으으으.... 성 $\bigcirc$ (만 4세): (놀랐는지 멈칫하고 민으랄을 잡는다.)아.. 으.. 아냐...

민 $\bigcirc$ (만 5세): (성ㄱㄱㅏ 팔을 잡자 더 서럽게 운다.)으아아 앙!!

성 $\bigcirc$ (만 4세): (당황했는지 팔을 잡은 손을 놓는다.)

(M 어린이집, 2015. 07. 13)

관찰 9는 남자 유아들이 애니메이션의 한 장면을 표현하 고 있는 상황이며 애니메이션 속 상황을 연출하기 위해 의성 어 - 의태어를 사용하여 극대화 하고 있는 모습을 살펴볼 수 있 다. 함께 애니메이션이 공유가 되지 않으면 관계를 맺고 놀이 를 지속할 수 없는 상황이며 의성어 · 의태어 사용은 애니메이 션 속 캐릭터들의 행동을 보여주기 위해 사용되고 있다. 신체 즉 움직임을 표현하기 위한 의성어·의태어는 놀이를 공유할
수 있게 해주었으며 관계가 유지될 수 있도록 해주었다.

\section{놀이에서 나타난 유아 의성어·의태어의 의미}

유아의 의성어-의태어 사용이 어떤 의미를 갖는지에 대한 물 음의 답은 유아를 보다 깊이 이해하고, 이러한 이해를 바탕으 로 사려 깊고 적절하게 행동할 수 있다는 교육적 함의를 고찰 하는데 있다. 유아가 놀이 속에서 의성어 - 의태어를 사용하여 상대방에게 생각과 사고를 전달하고 표현하는 과정들은 단순 하게 많이 사용되는 언어형태로만 예측하여 바라볼 것이 아니 었다. 의성어 - 의태어의 독특한 특성들인 함축성, 은유성, 반복 성, 유연성, 개인적인 표현의 폭이 넓게 허용되는 특성들이(S. B. Bae \& Park, 2012; Chae, 2002; You, 2003) 놀이 속 유아의 언 어를 매끄럽게 해주었고, 언어를 풍부하게 사용할 수 있도록 해주었으며, 상상하는 모든 것들을 언어로 쏟아내게 해주었다.

놀이가 점차 견고하게 완성되어가는 과정 속에서 의성 어 - 의태어는 윤활유, 확장제, 기폭제 같은 무엇을 첨가하여 본 성질의 것을 유익하게 만들어주는 역할을 해주었다. 다음 은 의성어-의태어가 놀이에서 어떠한 의미인가에 대한 연구 결과이다.

\section{놀이 속 언어를 매끄럽게 하는 윤활유}

의성어-의태어가 가지고 있는 언어의 유연성(Chae, 2003; Saussure, 1983/1990)은 놀이의 지속성이라는 측면에서 매끄러 운 의사소통을 가능하게 해주는 역할을 하였다. 놀이에서 일 어나는 의사소통이라는 현상은 논리적인 모습과 비논리적인 모습이 혼용되어 나타나는데 이때 의성어-의태어는 유연한 모습으로 의사소통에 영향을 미쳤다. 놀이 전개 과정에서 의 성어 - 의태어는 구체적으로 나타나며 함께 놀이를 공유하는 상대방과 생각과 느낌을 이해할 수 있도록 해주었고 매끄러 운 의사소통을 가능하게 하였다. 의성어-의태어가 갖고 있는 유연성이라는 특성은 기계에 마찰면에 생기는 마찰력을 줄이 거나 마찰면에서 발생하는 마찰열을 분산시킬 목적으로 사용 되는 물질인 윤활유(Lubricating oil; Doosan Corporation, n.d.) 같은 첨가제 역할이 되어주었다. 다음 관찰을 살펴보면 의성 어·의태어의 유연함으로 놀이가 매끄럽게 흐르고 있는 상황 을 살펴볼 수 있다.

관찰 10

지 $\bigcirc$ (만 5세): (청진기를 그림책에 대고) 흠..멜랑대고 있 
어요! 약이 필요하군요...

예 $\bigcirc$ (만 5세): 약 여기 있어요 (아주 가느다란 목소리를 흥내내며)

지 $\bigcirc$ (만 5세): 자 아시겠죠? 이러다 비틀거려요. 약이요! 잘 먹어야합니다! 꼬박꼬박

지 $\bigcirc$ (만 5세): 아니!!! 뭐요? (무언가에 놀라는 듯한.. 상대 는 의자)

예 $\bigcirc$ (만 5세): 후다다닥!! 여기습니다.

지 $\bigcirc$ (만 5세): 비틀비틀하면 안되요. 빨리 빨리 일어나야 죠! (의자를 쓰다듬는다.)

예 $\bigcirc$ (만 5세): 약을 다시 지어야겠어요. (약을 다시 병원 놀이 가방에 주워 담으며)

(M 어린이집, 2015. 07. 13)
어-의태어는 공감각적으로 용법을 넘나들기 때문에 다양한 표현의 묘미를 엿볼 수 있다(Chae, 2003). 하나의 의성어·의 태어가 다양한 뜻을 지니고 있기 때문에 가능하며, 이것은 언 어를 풍부하게 하고 그 풍부함이 놀이 또한 풍부하게 만들어 준다. 다음 관찰에서 살펴볼 수 있다.

관찰 11

하(만 3세): 라면 주세요.

경 $\bigcirc$ (만 3세): 네 라면이요! 잠시만요. 쓱쓱 싹싹! 쓱쓱쓱 싹싹싹 (칼질하는 행동을 하며) 보글보글 맛있겠다! (냄 비에 라면 넣는 행동을 하며) 자 라면이요!

하(만 3세): (건네받은 그릇을 받아들고) 후루루룩, 쩝 쩝. 후루룩! 맛있다!

(S 어린이집, 2015. 08. 17)

위의 관찰 상황을 살펴보면 유아들이 의성어 - 의태어를 매 끄럽게 사용하여 놀이를 완성해가는 모습이 잘 나타나있다. 관찰 10 의 놀이 상황에서 사용된 “비틀비틀” "꼬박꼬박”은 반 복형에 속하는 의성어-의태어다. 의미상 복수성, 계속성, 반 복성 등을 표현하는 의성어·의태어로(Chae, 2003) 예를 들어 '비틀거리다'가 일회적 동작이라면 '비틀비틀 거리다'는 반복 적 동작을 가리키며 뜻을 더 확장시킨다는 것을 알 수 있다. 자 신의 동작을 확장시키며 상대방에게 의성어 - 의태어를 사용 하여 표현하고자 하는 유아들의 모습에서 유능한 모습을 엿볼 수 있다. 자신의 의도를 의성어 - 의태어를 적절하게 사용하여 상대방에게 정확하게 전달하는 모습을 통해 놀이가 매끄럽고 유연하게 진행되고 있음을 살필 수 있었다.

놀이를 공유하는 과정 속에서 의성어 - 의태어라는 언어 형 태는 매끄러운 의사소통을 가능하게 하며 막힘없이 유연하게 놀이가 진행될 수 있게 해주었으며, 이것은 바로 놀이를 지속 시키고 나아갈 수 있게 하는 첨가제 같은 윤활유의 모습으로 의성어·의태어가 사용되고 있음을 유감없이 보여준다.

\section{놀이 속 언어를 풍부하게 만드는 확장제}

의성어-의태어는 놀이를 풍부하고 풍성하게 만들어주는 원 천이 되어 액체 또는 고체의 표면에 소량의 액체 방울을 얇 은 피막으로 하는데 도움이 되는 물질인 확장제(Sehwa on the Editorial Department, 2001) 같은 역할을 하였다. 유아의 표현 에 의성어-의태어를 덧입힘으로써 놀이 구성이 보다 풍성하 게 만들어지는 현상을 관찰을 통해 살펴볼 수 있었다. 본래 언 어가 갖는 정의는 해석의 범위가 한정될 수밖에 없지만 의성
관찰 11 속 유아들은 소꿉놀이를 하고 있다. 놀이가 시작되 면서 유아들은 아무 말 없이 부지런히 소꿉놀이 장난감을 바 닥 한 곳에 모았다. 모아진 소꿉놀이 장난감을 잘 정돈하고 누 가 먼저랄 것 없이 하아 “라면 주세요.”라고 놀이를 시작한 다. 경도도 놀이가 시작되었다는 것을 잘 알고 있다는 듯이 "잠 시만요.”라고 대화를 이어간다. 경 $\bigcirc$ 는 칼질하는 행동을 하며 “쓱쓱싹싹”이라는 의성어 - 의태어를 사용하는데 자신의 행동 을 상대방에게 알리고자 하는 의도가 엿보였다. 칼질하는 행 동이 끝나자 빈 장난감 그릇에 라면을 넣는 행동을 하며 “보글 보글”이라는 의성어·의태어를 사용하는데 라면이 맛있게 되 었다는 것을 표현하고자 하는 모습을 살펴볼 수 있었다.

이처럼 위의 관찰에서 사용되고 있는 의성어 - 의태어는 풍 부한 표현으로 유아가 전달하고자 하는 것을 다양하게 만들어 주었으며 놀이 또한 풍성하고 풍부하게 해주었다. 이것은 의 성어·의태어가 갖고 있는 은유적이고 반복적인 특성이 언어 를 풍부하게 만들고 놀이를 확장시켜주고 있다는 것을 살필 수 있었다.

\section{놀이 속 언어 상상을 폭발하게 하는 기폭제}

새로운 것을 만들어 내는 인간의 행위는 창조적 행위 (Vygotsky, 1930/2014)로 불리며 아동은 자신이 겪었던 것을 단 순하게 반복하는 것이 아니라 자신이 경험한 것 느낀 것을 새 롭게 나타내며 이것은 창조적 행위에 기반을 둔다. 놀이 속에 서 유아는 현실과 상상을 넘나들며 자유자재로 놀이를 만들어 내는데 이때 의성어·의태어는 유아가 상상하는 것을 표현하 
기 위한 도구로 사용된다. 상상 속 이야기를 표현할 때 나타나 는 의성어 - 의태어는 유아들의 세계에서 새롭게 만든 말로 독 창적인 언어로 표현된다. 이것은 의성어-의태어의 신조어라 는 범주에 속하며 개인이 자체적으로 신조어를 만든다 하더 라도 개인이 표현할 수 있는 폭이 넓게 허용되는 특징(Chae, 2002; Im, 2015)으로 유아들이 새롭게 만든 말이더라도 사회 성을 획득할 수 있다.

다음의 관찰을 통해서 유아가 어떻게 새롭게 언어를 만들 어내는지 유아의 유능하고 창조적인 면모가 유감없이 발현되 는 모습을 살펴볼 수 있다.

\section{관찰 12}

도 $\bigcirc$ (만 4세): 우리 기린 촉촉이 만들자.

승 $\bigcirc$ (만 4세): 기린 촉촉이?

도 $\mathrm{O}$ (만 4세): 응 기린 촉촉이. 완전 작은 기린 촉촉이 만 들거야.

승ㅇㅁ만 4세): 응 그래!!

도 $\bigcirc$ (만 4세): 기린 촉촉이! 넌 모만들거야?

승 $\mathrm{O}$ (만 4세): 나도 기린 촉촉이! 아니다! 난 뱅뱅이 만들 거야.

도 $\bigcirc$ (만 4세): 뱅뱅이 만든다고? 흠....

승 $\bigcirc$ (만 4세): 응 너도 뱅뱅이 만들어서 가지고 놀자!

도 $\bigcirc$ (만 4세): (자신이 만들고 있는 블록을 잠시 보더니) 그래! 뱅뱅이 만들어서 가지고 놀자.

(S 어린이집, 2015. 09. 14)

위의 관찰에서 나타난 의성어 - 의태어는 유아들이 새롭게 만들어낸 신조어다. “촉촉이”라는 표현은 과거 유아들이 수업 시간에 기린이 침을 많이 흘린다는 지식을 바탕으로 만들어낸 의성어 · 의태어다. 또한 “뱅뱅이”라는 의성어·의태어 역시 유아들이 새롭게 만들어낸 신조어인데 무언가가 돌아가는 모 습에 만들어진 의성어 - 의태어다. 이처럼 유아들이 새롭게 만 들었지만 그 뜻이 함께 통용되고 있기에 “촉촉이”와 “뱅뱅이” 는 신조어라는 새로운 언어가 창조되었는데, 약간의 충격이나 마찰, 감전으로 쉽게 발화하여 작약이나 폭파약을 폭발시키는 데 쓰이는 화약을 뜻하는(NIKL, 1999) 기폭제 같이 언어 상상 을 폭발하게 해주었다. 놀이 속에서 상상한 것을 의성어 - 의태 어로 표현하며 상상한 것을 함께 공유하는 과정 속에서 유아 들의 사회 안에서 새롭게 만들어진 언어는 그들만의 문화 안 에서 의사소통이 가능한 형태로 사회성을 획득하고 있는데, 이는 의성어 - 의태어가 갖고 있는 특성 중 사회성을 획득할 수
있는 특성으로 유아들의 언어 상상을 폭발하게 해주었다.

\section{논의 및 결론}

본 연구는 의성어- 의태어가 유아 언어 사용의 $50 \%$ 를 차지한 다는 선행연구(Y.-T. Kim et al., 2014)를 기반으로 유아들의 놀 이라는 자연스러운 상황에서의 의성어 - 의태어 사용 현상을 관찰함으로써 의성어 - 의태어가 유아 언어 사용에 어떤 의미 를 갖는지 밝히고자 하였다. 그리하여 의성어 - 의태어가 유아 언어 사용에 중심이 되어 표현하고 있음을 확인하였다. 연구 결과의 내용을 다음과 같이 요약하고 논의를 제시한다.

첫째, 놀이 상황에서 사용된 의성어·의태어는 크게 세 가 지 유형으로 첫 번째 움직임을 표현하는 유형, 두 번째 소리를 표현하는 유형, 세 번째 형태를 표현하는 유형으로 나타났다. 의성어 - 의태어 개념(Chae, 2003)을 토대로 분류한 위의 유형 들은 놀이가 갖고 있는 근본적인 성질인 자유로움(M. Y. Sung, 2014)이 바탕이 되어 신체를 표현하고자 하는 목적, 소리를 표현하기 위한 방안, 사물의 형태를 표현하는 방안으로 의성 어 - 의태어를 사용하였다. 관찰을 통해 살펴본 의성어 - 의태 어는 그림책, 동요, 애니메이션 등의 다매체에서 표현된 예측 가능한 형태(Chae, 2003)와는 다른 형태였으며 기존에 볼 수 없는 색다른 모습이었다. 이러한 결과는 유아 언어를 이해하 기 위해서는 유아들이 사용하는 의성어-의태어 형태에 대해 파악해야 할 필요가 있으며, 이러한 의성어 - 의태어 자료들은 유아와 관련된 다매체에서 적극 활용하여 기술되어질 필요가 있다.

둘째, 우리 주변에 존재하고 있는 생활세계의 기본적인 주 제들인 공간과 신체 그리고 시간, 타인 혹은 사물과의 관계라 는 네 가지 실존적 근거(van Manen, 1990)들은 의성어 - 의태어 가 다양한 유형으로 존재할 수 있는 바탕이 되어주었다. 위의 실존적 근거를 토대로 공간, 신체, 관계는 하나의 그물망에서 서로 영향을 받으며 유아 언어 사용에 영향을 미쳤다. 놀이가 이루어지는 공간은 유아의 움직임을 동적 혹은 정적으로 만들 어주었고 유아들의 관계 또한 소그룹과 대그룹으로 결속시키 는 힘이 되었다. 즉 의성어-의태어가 갖고 있는 공감각적 언 어 표현 특징(Chae, 2003)이 위의 생활세계의 변화(van Manen, 1990)에 반응하며 존재하였다. 하지만 본 연구가 놀이라는 생 활세계만을 고려하여 진행되었다는 점은 의성어·의태어의 존재 모습 또한 놀이가 갖는 자유로움이라는 특징에 국한되어 나타났을 가능성이 크다. 그러므로 학습 공간 생활세계 및 가 
정 속 생활세계의 의성어 - 의태어 사용 관찰 탐구가 이루어진 다면, 유아의 언어 발달에 의성어 - 의태어가 언어 습득 빈도를 높이므로(S. B. Bae \& Park, 2012) 유아 교육 측면에서 언어 발 달에 도움을 줄 수 있을 것이다.

셋째, 의성어·의태어의 유연한 특성, 공감각적 특성, 표현 의 제한이 없는 특성들은 유아가 다채롭게 언어를 사용할 수 있게 해주었다(S. B. Bae \& Park, 2012; Chae, 2003; You, 2003). 문법체계라는 틀에서 자유롭지 못한 유아에게 의성어 - 의태 어는 생각과 사고를 확장할 수 있도록 도와주는 역할을 하였 고, 새로운 언어를 창조하는 것을 가능하게 해주었다. 유아 언 어가 풍부해짐으로써 놀이 자체 또한 풍부해졌고 의사소통에 어려움이 없도록 하였다. 이러한 결과를 통해 수동적인 학습 자가 아닌 능동적으로 언어를 구사하는 유능한 유아를 볼 수 있었다. 그러므로 의성어 - 의태어 사용 독려는 유아의 언어 능 력을 높일 수 있는 긍정적인 효과를 기대해 볼 수 있을 것이다.

위의 내용들을 바탕으로 결론을 제시하면, 끊임없이 상상 의 세계가 펼쳐지는 놀이 속에서 유아들은 상상 공간을 창조 해냈고, 상상에서 존재하는 환상을 이야기하면서 유아들은 놀 이를 공유했다. 그리고 그 중심에는 의성어 - 의태어가 유아들 의 의사소통을 담당하는 역할을 자처하고 있었다. 이처럼 유 아들의 의성어 - 의태어 사용은 감각적 경험 즉 놀이 경험과 언 어 사이의 관계에 대한 이해를 높일 수 있었으며(S. B. Bae \& Park, 2012) 한국어 수준과는 관계없이 충분한 소통이 가능하 다(Y.-B. Choi, 2013)는 것을 보여주었다. 또한 의성어 - 의태어 는 윤활유, 확장제, 기폭제 같은 무엇을 첨가하여 본 성질의 것 을 유익하게 만들어주는 언어의 첨가제가 되어주었다.

이상의 연구결과를 바탕으로 제한점 및 후속 연구를 위한 제언을 덧붙이자면, 첫째, 본 연구를 위해 참여한 두 곳의 어 린이집 중 $\mathrm{M}$ 어린이집에서 의성어 - 의태어 사용이 더 풍부하 게 나타났는데 어떤 차이로 인한 까닭인지 밝히는 것은 어려 움이 있었다. 두 곳의 연구 환경과 조건이 각각 달랐고 연구문 제를 토대로 분석된 코딩이었기 때문이다. 따라서 향후 연구 에서 두 곳의 연구 기관을 선정하여 연구 환경 설계를 최대한 비슷하게 한 후 의성어 - 의태어 사용을 살핀다면 그 차이의 까 닭을 발견할 수 있을 것으로 보이므로 보완 연구가 필요해 보 인다. 둘째로 이 연구는 놀이 상황이라는 연구 배경에만 초점 이 맞춰져있어 실제 수업이 이뤄지는 상황에서의 의성어·의 태어 사용은 살피지 못했다. 하지만 의성어 - 의태어가 성인과 의 상호작용에서 자신의 사고를 확장시키는데 중요한 요인으 로 작용하기 때문에(Jang, 2015) 교사가 교육적 측면에서 어떻 게 실천할 수 있는지에 대한 후속연구도 필요하다. 셋째로 의
성어 - 의태어 사용 연령을 유아로 제한하여 살펴보았는데, 영 아의 의성어-의태어 사용에 대해 살펴본 선행연구가 없다 는 점에서 아직 언어표현이 미흡한 영아의 의성어·의태어 사 용이 영아 언어 발달에 어떤 영향을 미치는가에 대한 후속 연 구가 절실하다. 이와 같은 연구의 한계에도 불구하고 본 연구 는 아직 시도되지 않았던 유아의 의성어 - 의태어 사용을 살핌 으로써 유아 언어 사용에 대한 이해를 넓혔다는 점에서 의미 가 있다. 이와 더불어 본 연구에서 실제 유아들이 사용한 의성 어-의태어가 기존의 그림책, 동요, 애니메이션 등의 기성품처 럼 비슷한 의성어·의태어 유형들을 벗어나 색다른 모습들도 나타났다는 점에서 다양하고 좀 더 풍부한 매체구성이 이뤄질 수 있는 자료가 되기를 기대한다.

\section{Notes}

This article is a part of the first author's master's thesis submitted in 2016, and was presented at the 2016 Annual Spring Conference of the Korean Association of Child Studies.

\section{Conflict of Interest}

No potential conflict of interest relevant to this article was reported.

\section{References}

\section{In Engligh}

van Manen, M. (1990). Researching lived experience: Human science for an action sensitive pedagogy. New York: State University of New York Press.

van Manen, M., \& Michael A. (2012). Ethical responsivity and pediatric parental pedagogy. Phenomenology \& Practice, 6(1), 5-17.

Wolcott, H. F. (1990). Writing up qualitative research. London: Sage.

\section{In Korean}

Ahn, S.-R. (2014). An ethnographic study on children's characteristics of language development with imaginative 
play (Master's thesis). Retrieved from http://www.riss.kr/ link? id=T13525726

Bae, H. S. (2006). The study of teaching method about Korean onomatopoeic words and mimetic words for foreigner. The Korean Society of Bilingual Research, 31, 97-121. Retrieved from http://www.riss.kr/link?id=A75596164

Bae, S. B., \& Park, H. W. (2012). The use of onomatopoeic language in korean children-caregiver interactions. The Korean Journal of Developmental Psychology, 25(1), 101-115. Retrieved from http://www.riss.kr/link?id=A100634161

Bai, D.-Y. (2013). A study on the base research for development of onomatopoetic and mimetic words textbook for KFL learners. Urimal, 32, 159-184. Retrieved from http://www. riss.kr/link?id=A1006341617

Chae, W. (2002). A study of onomatopoeia from a textgrammatical point of view. The Korean Language and Literature, 132, 121151. Retrieved from http://www.riss.kr/link?id=A19746008

Chae, W. (2003). Onomatopoeia and mimetic word in Korean. Seoul: Seoul National University Press.

Choi, H. J., \& Lee, K. E. (2009). A study on the onomatopoeia and mimetic word list and education in Korean language education. Proceedings of the Korean Language and Culture Education Society, 1, 117-126. Retrieved from http://www. riss.kr/link?id=A60024634

Choi, Y.-B. (2013). Education method using nursery rhymes with onomatopoeia: focusing on the roles of immigrant wives of korean men as child-rearers and educators. The Journal of Korean Arts Education Research, 22, 85-120. Retrieved from http://www.riss.kr/link?id=A99727463

Choi, Z. (2009). Zur untersuchung der phänomenologie merleaupontys und husserls im hinblick auf den begriff des leibes: Eine phänomenologische untersuchung des leibes. Philosopy and Phenomenology, 40, 1-33. Retrieved from http://www. riss.kr/link?id=A76369637

Doosan Corporation. (n.d.). Doopedia [web page]. Retrieved from http://www.doopedia.co.kr

Graue, M. E., \& Walsh, D. J. (2014). Studying children in context (W. H. Hong, G. H. Lee, J. H. Bae, \& H. W. Jung, Trans.). Ilsan: Powerbook. (Original work published 1998)

Im, Y.-J. (2015). Wittgenstein's "language game" and "philosophy with children" (Doctoral dissertation). Retrieved from http:// www.riss.kr/link?id=T13747380

Jang, H.-J. (2015). An ethnographic study on private conversation among five-year-olds at a kindergarten (Doctoral dissertation). Retrieved from http://www.riss.kr/link?id=T13819243

Jeon, G. (2013). Phenomenological study on children's relationshipmaking revealed in play (Doctoral dissertation). Retrieved from http://www.riss.kr/link?id=T13143555

Jeon, G. (2015). Phenomenological study on the features and meanings of local playground. Korean Journal of Early
Childhood Education, 35(3), 337-363. Retrieved from http://www.riss.kr/link?id=A100545896

Jo, C. G. (2005). How to teach onomatopoeia and mimetic words. The Linguistic Association of Korea Journal, 13(3), 61-84. Retrieved from http:///www.riss.kr/link?id=A358933

Kang, N. (2014). A study of language socialization of Korean children (Doctoral dissertation). Retrieved from http://www.riss.kr/ link?id=T13440528

Kim, S. J. (2014). A study on the teaching of Korean onomatopoeic and mimetic words. Language Facts and Perspectives, 33, 169-190. Retrieved from http://www.riss.kr/ link?id=A100038438

Kim, Y.-T., Yang, M.-S., \& Lim, W.-J. (2014). The effect of the language education using onomatopoeia and mimetic words for the development-delayed children's expressive language. Korean Journal of Early Childhood Special Education, 14(4), 195-219. Retrieved from http://www.riss.kr/ link?id=A100261360

Lee, J.-E. (2013). The characteristics of young children's narratives during block play. Korean Journal of Early Childhood Education, 15(2), 157-182. Retrieved from http://www.riss. $\mathrm{kr} /$ link?id=A100029855

Nam, P. H. (1993). Onomatopoeia and mimetic words of middle Korean. The New Korean Life, 3(2), 93-115. Retrieved from http://www.riss.kr/link?id=A19640504

Oh, K. R., Choi, Y. H., \& Jeon, J. S. (2014). The effect of playfulness and creativity on physical activity model for kindergarten curricula. Korean Journal of Physical Eduaction, 53(3), 201-211. Retrieved from http://www.riss.kr/ link?id=A100031837

Pence, K. L., \& Justice, L. M. (2010). Language development from theory to practice (S. S. Kim, H. S. Kim, \& S. G. Lee, Trans.). Seoul: Hakjisa. (Original work published 2008)

Roh, J. (2005). Ordinary life plays as musical activities: Objectives and methods. Journal of Music and Human Behavior, 2(1), 47-65. Retrieved from http://www.riss.kr/link?id=A77013266

Saussure, F. (1990). Course in general linguistics (S. U. Choi, Trans.). Seoul: Minumsa. (Original work published 1983)

Sehwa editorial. (2001). Chemistry. Seoul: Sehwa.

Sung, K.-O. (1993). Poetic status and functions of onomatopoeic words and mimetic words. The New Korean Life, 3(2), 116133. Retrieved from http://www.riss.kr/link?id=A19640506

Sung, M. Y. (2014). Use of contextualized and decontextualized talk in preschoolers' peer play. The Journal of Korean Home Management Association, 32(5), 31-40. Retrieved from http://www.riss.kr/link?id=A100133526

The National Institute of the Korean Language. (1999). A standard Korean dictionary. Seoul: Doosan Dong-a.

Vygotsky, L. S. (2014). Child's imagination and creativity (Association for Vygotsky Research., Trans.). Seoul: 
Salimtea. (Original work published 1930)

Yeu, H. R. (2015). Logic and methods of phenomenological research: Max van Manen's perspectives of hermeneutic phenomenological research methodology. Journal of Family and Counseling, 5(1), 1-20. Retrieved from http://www.riss. $\mathrm{kr} / \mathrm{link}$ ? id=A100427132

You, Y. C. (2003). La motivación lingüística y la formación de palabras. Estudios Hispanicos, 26, 163-184. Retrieved from http://www.riss.kr/link?id=A30085379

\section{ORCID}

Yoon Mi Kim

Eunju Yun

http://orcid.org/0000-0003-0122-5087

http://orcid.org/0000-0002-3641-8834

Received October 31, 2016

Revision received January 15, 2017

Accepted February 6, 2017 